\title{
Pediatric and Maternal HIV in Texas Border Counties and Urban Area
}

Author: Jessie Ho,

Faculty Mentor: Joseph Oppong, Department of Geography, College of Arts and Sciences;

Toulouse School of Graduate Studies

Department and College Affiliation: Texas Academy of Math and Science 


\section{Bio:}

Jessie Ho is a 2011 graduate of the Texas Academy of Mathematics and Science. She will be at the University of Texas in Dallas next year with an Academic Excellence full scholarship. Ho will be majoring in biology with the career goal of pursuing an M.D. and working in international health. She has been on the Dean's List and President's List for every semester at UNT. Her research led her to become a Young Epidemiological Scholars 2011 Regional Finalist and scholarship winner. She has presented her research in Washington, D.C for the YES Competition and at UNT's Scholar Day 2011. She was also McConnell Hall's Eco Rep and Environmental Club President through the 2010-2011 school year. She has always been active in community service around both UNT and the Dallas-Fort Worth community. Ho is currently spending her summer giving presentations at the Museum of Nature and Science Planetarium as a volunteer and working over 20 hours a week as a restaurant hostess. 


\begin{abstract}
:
This study examines the geography of pediatric HIV, HIV in women, and age at diagnosis of women in the Dallas Fort-Worth Metroplex, Houston-Galveston Area, and the colonias of TexasMexico border counties using the human ecology model. In addition, the study investigates the correlation of female HIV rates and female age at diagnosis with pediatric HIV. County-level morbidity data from the Texas Department of State Health Services (TDSHS) from 1980-2009 are analyzed. Pediatric HIV and HIV in women have a strong positive correlation. The border counties have lower rates of HIV than do the urban areas, and have the youngest age at diagnosis, but have a higher pediatric HIV rate than Dallas Fort-Worth Metroplex. Interventions should target preventing HIV in females.
\end{abstract}




\section{Introduction}

While the HIV epidemic began predominantly as a male homosexual disease, females worldwide have been infected at increasing rates. In fact, in parts of Africa, more females than males have been infected with HIV. If new HIV infections continue at their current rate worldwide, women with HIV may soon outnumber men with HIV (CDC, 2010). Women are most commonly infected through sharing contaminated needles during drug use or unprotected sex with an infected male. In 2008, there were 13,795 women living with HIV in Texas (TDSHS, 2010). The difference between HIV in women and in men is that women can pass on the disease to their children during childbirth or through breastfeeding.

At the end of 2007, there were 2,919 children under the age of 13 living with HIV in 37 states and in five U.S. dependent areas with HIV reporting (CDC, 2010). Of the cumulative 8,797 pediatric HIV cases, defined as HIV in children under 13, that were reported in the U.S., $92 \%$ were transmitted perinatally. Perinatal transmission of HIV is the vertical transmission of HIV from a mother to child during childbirth or breastfeeding. Since the 1990s, perinatal transmission has been declining throughout the country due to more routine HIV screenings of women and more effective preventive measures (MMWR, 2010). The recommendation of the Centers for Disease Control and Prevention (MMWR, 2003) that all women be tested for HIV, in conjunction with the expanded HIV surveillance system, has aided in the decline of perinatal HIV (MMWR, 2003). The key to maximizing perinatal HIV prevention is to provide prenatal care, to diagnose HIV infection before delivery, and to offer the most effective medical interventions (Peters, et al., 2008). The primary way of preventing mother-to-child HIV transmission, through both childbirth and breastfeeding, is to provide the mother with antiretroviral treatments during prenatal care. 
In this study, I examine both HIV in women and pediatric HIV in the two urban areas with the highest rate of HIV prevalance in Texas, Houston-Galveston area and the Dallas area, and the Texas-Mexico Border. As defined by the Texas Department of State Health Services, the twelve counties of the Dallas-Fort Worth and the six counties of the Houston-Galveston contain over half the persons living with HIV in Texas (TDSHS 2010). The Texas-Mexico border is home to growing cities and clusters of impoverished areas called colonias. A colonia, as defined by the Texas Office of the Secretary of State (TSOS), is "a residential area along the TexasMexico border that may lack some of the most basic living necessities, such as potable water and sewer systems, electricity, paved roads, and safe and sanitary housing" (TSOS, para. 1). Colonias lack the basic infrastructure necessary for water and electricity access.

Though colonias are present along the Mexican border with New Mexico, Arizona, and California, Texas has the largest number of colonias and colonia population (Wallisch, 1998). About 400,000 people in Texas live in almost 3,000 colonias along the border (TSOS). Despite the general definition of a colonia, colonias can vary largely in size and structure. Approximately $64.4 \%$ of colonias residents are hard-working legal U.S. residents and not illegal, undocumented residents (Anders et al., 2008). The majority of the residents in colonias are Hispanic. Colonias have high unemployment rates (ranging from 20\% to 60\%), very low median income (average of less than $\$ 834$ a month), and low levels of education. About $70 \%$ of colonias residents do not have a high school degree (Mier et al., 2008). Due to low access to health care and high poverty rates, colonia residents generally report worse physical health than does the general U.S. population.

This study aims to explore differences in the pediatric HIV and age at HIV diagnosis in women between the colonias and the urban areas. The colonias present a stark contrast in living 
conditions and lifestyle in comparison with highly developed and urbanized areas such as Collin County, the county with the highest median income in Texas. The differing demographic characteristics and socioeconomic status presents very different health characteristics in the colonias. The central research question is whether in comparison to women in urban areas, those from impoverished colonias exhibit higher rates of pediatric HIV due to low socioeconomic status and infection at a much younger age. The earlier a woman is infected, the more years of childbearing she has remaining, and the greater chances she has to pass on the HIV to her child.

\section{Hypotheses}

Hypothesis 1. Counties with a lower median income will have a younger average age at diagnosis in women and a higher rate of pediatric HIV.

Women in lower-income areas often have less than high school education and less money to buy contraception. A 1996 study on HIV risk behaviors in women in impoverished areas shows that younger women tend to engage in higher risk behaviors such as injecting drugs, and are less inclined to use condoms (Sikkema, et al., 1996). This increases vulnerability in the lower-income areas due to the congregation of vulnerable people who, in the lower socioeconomic status, engage in risky behaviors. As women contract HIV at a younger age, they are more likely to pass it on to their children. If they are infected at or before reaching childbearing age and are not aware of their infection, they may not get the necessary prenatal treatment, especially if they do not have insurance or money to pay for antiretroviral treatments or prenatal care.

Hypothesis 2. Counties with a higher unemployment rate, uninsured population, and low primary care provider rate will have less access to healthcare and a higher rate of pediatric HIV. 
Access to healthcare is probably the biggest determinant of whether a mother will transmit HIV to her child. Antiretroviral treatments can prevent transmission through childbirth and breastfeeding. In order to get prenatal care, mothers must go through a primary care physician or an obstetrician or gynecologist. Prenatal care is measured through the physician rate. But even if there are many physicians in an area, people may not have regular check-ups because they are uninsured. The uninsured often choose to wait until the last minute before going to the emergency room rather than pay for regular doctor visits. Thus, counties with less access to health care would exhibit a higher pediatric HIV rate. Because colonias have worse socioeconomic status, we expect higher rates of pediatric HIV and women diagnosed at much younger ages.

Hypothesis 3. Counties with a higher percentage of blacks and Hispanics will have higher rates of pediatric HIV and a younger average age of diagnosis in women. While Blacks constitute only $13 \%$ of the U.S. population, the uninsured rate is more than oneand-a-half times that of Whites (Kaiser Family Foundation 2000). Moreover, 23\% of all Blacks are uninsured while $21 \%$ have Medicaid. People are much less likely to have regular checkups and HIV tests if they do not have insurance. Knowledge of the infection and access to prenatal care are the most important ways to prevent perinatal transmission. Therefore, it may be more likely for Black women to transmit HIV to their unborn children due to their high uninsured rate. In the CDC's analysis of perinatal HIV from 2004 to 2007, race and ethnicity proved to be a risk marker. From 2004 to 2007, 69\% of perinatal infections were in Blacks while $16 \%$ occurred in Latinos (MMWR, 2010). Blacks and Hispanics together constitute $85 \%$ of the total perinatal HIV cases. The race and ethnicity breakdown of perinatal HIV cases is mirrored in the HIV cases of women over 13 years of age. The increased susceptibility for Blacks and Hispanics 
makes race and ethnicity a characteristic to monitor when evaluating risk factors and markers. With the high percentage of Hispanic population in the colonias, a higher pediatric HIV rate, female HIV rate, and younger age at diagnosis is expected.

Hypothesis 4. Counties with a lower age at diagnosis in women will have a higher pediatric HIV rate.

Because the majority of the pediatric HIV cases are transmitted perinatally, a woman would have to have contracted the disease before or during her childbearing years to transmit it. Thus if a county has a younger average age at diagnosis in women, then there is a higher chance the disease will be passed on to their children.

Hypothesis 5. Counties with a higher female HIV rate will have a higher pediatric HIV rate.

Because over $90 \%$ of pediatric cases are transmitted perinatally, the baby will not contract HIV unless the mother has the infection.

\section{Methodology}

For this study, the Dallas Fort Worth Area is defined as Collin, Dallas, Denton, and Tarrant Counties. The Houston-Galveston Area is defined as the 13 counties represented in the Houston Galveston Area Council: Austin, Brazoria, Chambers, Colorado, Fort Bend, Galveston, Harris, Liberty, Matagorda, Montgomery, Walker, Waller, and Wharton (HGAC, 2008). The Texas Secretary of State (TSOS) defines colonias counties as counties containing a colonia within 150 miles of the Texas-Mexico border. The 29 counties that meet this definition are: Aransas, Brewster, Brooks, Cameron, Culberson, Dimmit, Duval, Edwards, El Paso, Frio, Hidalgo, Hudspeth, Jeff Davis, Jim Hogg, Kinney, Kleberg, La Salle, Maverick, Nueces, Pecos, Presidio, Reeves, Starr, Terrell, Uvalde, Val Verde, Webb, Willacy, Zapata. The counties 
containing a majority of the colonias are El Paso, Hidalgo, Cameron, and Willacy (Wallisch, 1998). In total, the study encompasses 46 counties. Refer to Figure 1 for counties.

Data on the independent variables, income and race/ethnicity in these counties, is obtained from the 2000 U.S. Census. The percent of uninsured population, unemployed persons and primary healthcare providers per 100,000, are from the Texas Health Ranking Data. The 1980-2009 data on the dependent variables, pediatric HIV mortality rates and HIV average age at diagnosis in women, are provided by the Texas Department of State Health Services. CDC defines pediatric HIV as HIV in children under 13 years of age (CDC, 2010d). The median age and median age of females in each county are retrieved from the US Census.

The female HIV rate is calculated by dividing the total female cases by the total female population in the county, and multiplying the quotient by 100,000 . Pediatric HIV rate is calculated similarly. The population under 13 years of age is also from the 2000 U.S. Census data.

Maps are created in ArcGIS and statistical analysis is completed with SPSS 17.0. Maps have differing scales corresponding to their respective data. The pediatric HIV data cannot be mapped using the same scale as that for HIV due to the extremely small number of cases in Texas. There are also a much smaller number of female HIV cases than total cases in the population at large, since men still comprise the majority of HIV cases in Texas.

\section{Variables}

The variables in this study include HIV diagnoses per 100,000 children under 13, female HIV diagnosis per 100,000 women, and age at HIV diagnosis in females as dependent variables. They will be compared to several independent variables including percent of uninsured population, unemployment rate, and primary care provider rate per 100,000, used as measures of 
access to health care. In addition, the study will examine race/ethnicity and median income as other possible risk markers.

\section{Results}

Figure 2 displays the geography of HIV in women in the study area. The map indicates that the Houston-Galveston Area has the highest rate of HIV in women. Webb and Dallas counties also have very high rates. Figure 2 is comparable to Figure 4, the map of the HIV rate in the 46 counties. The same counties appear to have the highest rates on the maps, Dallas, Harris, Walker, and Webb. Surprisingly the colonias counties appear to have the lowest HIV rate in females and among the overall population.

The pediatric HIV rate is displayed in Figure 3. The higher rates appear to be concentrated in the Houston-Galveston Area, though Pecos and Webb counties also have high rates. The only discernable pattern present in the map is the concentration in urban areas. Dallas, Tarrant, and the Houston-Galveston counties are the most highly urbanized areas in Texas. However, this conclusion is not completely supported by the information present in this map. Pecos and Webb counties are within the same rate range as Harris County, despite the presence of colonias and smaller cities. Together, Pecos and Webb make up about one-third of the total pediatric HIV cases in the colonias counties. El Paso is also an urban area of Texas but does not

follow the trend of a rate as high as that of the other two urban areas. In fact, the colonias region has a slightly higher pediatric HIV rate than the Dallas Fort Worth area-9.6 per 100,000 compared to 17.9 per 100,000 (Table 2).

Figures 2 and 3 present similar maps. In both maps, the highest rates appear in the Houston-Galveston Area, followed by the colonias counties, and then the Dallas region. All the counties containing zero female HIV cases similarly do not contain any pediatric HIV cases. 
This pattern is supported by a significant correlation $(\mathrm{r}=.696, \mathrm{p}=.000)$ between the pediatric and female HIV rates, suggesting that areas with higher female rates of infection are more likely to have a higher pediatric HIV rate (Table 1). There is no correlation between percent unemployed and primary care provider rate with female HIV, pediatric HIV, and age of HIV diagnosis in women. However, race and ethnicity have consistently significant correlations with both female and pediatric HIV rates.

Median income had a positive correlation with both pediatric HIV $(\mathrm{r}=.561, \mathrm{p}=.000)$ and HIV in women $(r=.449, \mathrm{p}=.002)$. In the 46 surveyed counties, higher-income areas appear to have higher rates of HIV in women and children. This is evident in both Figures 2 and 3. The colonias counties contain much larger populations of lower-income people living in the colonias, yet have the lowest rate of female HIV.

Access to healthcare was found to be insignificant. Of the three variables, primary care provider rate, percent unemployed, and percent uninsured, the only significant correlation was between percent uninsured and female HIV rates $(r=-.321, p=.03)$. In counties with a higher percent of uninsured population, there is a lower female HIV rate.

Percent Hispanic population is negatively correlated with both female HIV $(r=-.372, p=$ $.011)$ and pediatric HIV $(\mathrm{r}=-.440, \mathrm{p}=.002)$. While the HIV rate decreases with an increase of Hispanics in the 46 counties, it increases with an increase of Black population. There are strong positive correlations between the percent of total population that is Black and both pediatric HIV $(\mathrm{r}=.653, \mathrm{p}=.000)$ and HIV in women $(\mathrm{r}=.731, \mathrm{p}=.000)$. The percent of White population is not significantly correlated to the female HIV rate, but is positively correlated to pediatric HIV $(\mathrm{r}=.323, \mathrm{p}=.029)$. With an increase of White population there is an increase in pediatric HIV rate. The national pediatric HIV rate in White children is .5 per 100,000 , much lower than the rate in 
Black and Hispanic children. In this study, the percentage of Blacks in counties did exhibit a much stronger correlation with pediatric $\operatorname{HIV}(r=.653, \mathrm{p}=.000)$ rate than the percentage of Whites in counties $(\mathrm{r}=.323, \mathrm{p}=.029)$. On the contrary, the percentage of Hispanic population was negatively correlated with the pediatric HIV rate $(\mathrm{r}=-.440, \mathrm{p}=.002)$.

Figures 5 and 6 display a comparison of age at diagnosis and age structure in the three regions analyzed in this study. In all three regions, the average age at HIV diagnosis in the total population is higher than the average age at diagnosis in women. A stand-out observation of Figure 5 is the extremely young average age at female HIV diagnosis in the colonias counties. While the average age at diagnosis in all three regions and average of female HIV diagnosis in the Dallas Fort-Worth and Houston-Galveston areas linger above 30 years of age, the female average age at HIV diagnosis in colonias counties is 25 years. However, this younger age of diagnosis in the colonias counties did not have a significant correlation with pediatric HIV rates, as hypothesized. This probably reflects the larger number and higher median age of females diagnosed with HIV in the urban areas.

Figure 7 displays the race/ethnicity breakdown of the female HIV cases in each region. All of the races have an age at diagnosis in a small range of years. The only deviation is the age at diagnosis of over 45 years for other races in colonias counties. This is likely attributable to the small numbers problem, due to the small number of races other than Hispanic in the colonias counties.

\section{Discussion}

Because the majority of the pediatric HIV cases are transmitted perinatally, there will probably be fewer pediatric cases in counties that contain fewer infected women. When there are fewer women with HIV in the county, there is an already lower probability of having a high 
pediatric HIV rate in the county. A low female HIV rate, however, does not imply a low pediatric HIV rate. If a county with a high female HIV rate has excellent HIV treatment facilities, awareness, and access to prenatal care, then women would probably not transmit it to their children. The other variables (indicators of access to healthcare in the county) account for the possible anomalies between Figures 2 and 3. Dallas County has a high rate of female HIV but is not in the highest range of pediatric HIV, while Pecos County has a relatively low female HIV rate, yet a high pediatric HIV rate. The high pediatric HIV rate in Pecos County may also be a result of the small numbers problem.

Unexpectedly, counties with lower median incomes did not have higher pediatric and female HIV rates. Despite the very low socioeconomic status spread throughout the colonias counties, there are still low HIV rates. This is difficult to explain and may be attributed to a small sample size and small range of socioeconomic status due to the large disparity in income between the colonias and the urban areas.

The relatively low female and pediatric rate in the colonias counties can possibly be attributed to the Hispanic Paradox, as a majority of the colonias residents are Hispanic. The Hispanic Paradox suggests that Hispanics in the southwestern United States have a health status comparable to or better than that of Whites in the US, despite the generally low socioeconomic status of Hispanics (Markides and Eschbach, 2005). This proposal is evident in the negative correlation of female and pediatric HIV rates with Hispanic population and the relatively low HIV rates in the colonias counties. With a higher percentage of Hispanics in a county, there are lower pediatric and female HIV rates. Although that is found in this study, the HIV infection rate of Hispanic women is nearly four times that of White women in the US (CDC, 2010a). Hispanics in the US rank second to Blacks in HIV infection rate. Male-to-male sexual contact is one of the 
leading causes for the spread of HIV in the Hispanic population (CDC, 2010b). In many of the 29 counties on the border, there are few-to-no female HIV cases at all. While 1 in every 106 Hispanic women will be infected with HIV in her life, 1 in every 36 Hispanic men will be infected (CDC, 2010b). This gender disparity probably accounts for the relatively low rates of female HIV and pediatric HIV in the colonias counties.

The positive correlations with Black population and HIV correspond to the prevalence of HIV in Blacks in the US; Blacks make up $46 \%$ of the total HIV cases in the US (CDC, 2010a). In Sikkema et al.'s 1994 study of HIV risk behaviors in low-income housing, 82\% of the women surveyed were black (Sikkema et al., 1994). Much of the HIV infection is associated with low socioeconomic status and poverty that prevails among Black populations (Peterman, Lindsey, and Selik, 2005). Although in this study, a high percentage of the Black population correlated with a higher female and pediatric HIV rate, low median income is not correlated with a higher female and pediatric HIV. This may also be a result of the small numbers problem in the colonias counties. There are not only a small number of pediatric and female HIV cases in the colonias counties, but also a small number of Blacks. In many of the colonias counties, less than $1 \%$ of the population is Black. So the correlation of Blacks and HIV is visible in Figures 2 and 3. Since there are very small percentages of Blacks in the colonias counties, the Black population in the sample is concentrated in the urban areas. Both the Houston-Galveston and the Dallas-Fort Worth areas have high female and pediatric HIV rates.

The correlations and maps are all relative to the counties in the sample. Since the rest of Texas-which is majority White in central Texas and Black in East Texas-was not surveyed, it appeared that Hispanics had a low female and pediatric HIV. Because the pediatric and female HIV rate was smaller in the colonias counties than in the urban areas, the correlation between 
Hispanic population and HIV rates was negative. The correlation is a relative value that would be positive if evaluating the entire state of Texas. This is one of the major drawbacks of this study.

Lack of insurance is usually an indicator of low income, which is a known HIV risk marker. This is consistent with the negative correlation of percent uninsured. Despite the consistency, the correlations are likely inconclusive as a result of the small numbers problem and the small number of counties. The two counties, Edwards and Terrell, with the highest percent of the county population uninsured, almost $50 \%$ uninsured, have small total populations. Because of the small total population, there are naturally fewer HIV cases, especially female and pediatric cases. Terrell County has the highest percentage of uninsured population yet has no HIV cases. The small county population skews the results due to a lack of cases.

Overcoming the small numbers problem, Table 2 displays a direct comparison of the female and pediatric HIV rates among the 3 areas studied. The female HIV rate in Dallas is nearly three times that of the colonias, yet the colonias have a higher pediatric HIV rate. Although there is no significant correlation between access to healthcare and pediatric HIV, the lower rate in Dallas is evidence of the key role of healthcare in pediatric HIV transmission. When correlating healthcare using data from all 46 counties, there is no correlation due to the extremely high rates in the Houston-Galveston Area, an area with a dense population. However, when analyzing the female and pediatric HIV rates in just the region alone, computed with only the region's population, the difference in pediatric HIV rates is unequivocal. The severe lack of healthcare and prenatal care in the colonias probably causes more infected women to pass it on to their children. This finding supports the higher pediatric rate in Hispanics and lower-income areas without healthcare, thus underscoring the critical need of healthcare in the colonias. The finding also confirms that the higher pediatric HIV rates in Pecos and Webb counties than in the 
Dallas-Fort Worth counties is most likely due to lack of healthcare, not the small numbers problem.

The results of the graphs and Figures 5 and 6 are not entirely reflected in the correlations, probably because the graphs are a compilation of the region as an entity. The age at diagnosis in females is significantly correlated negatively with the percent of uninsured population. Thus, females are diagnosed with HIV at a younger age in counties with a higher percentage of uninsured population. The counties with the highest percentage of uninsured population are colonias counties, reflecting the results presented in the graph. What does not match the graph is the insignificance of the median income and Hispanic population correlations. A low median income and a large Hispanic population characterize the colonias counties, yet do not have a significant statistical correlation to either female HIV or to pediatric HIV. The inverse relationship between the low age of diagnosis and the colonias counties is only visible in the HIV rates computed separately by region (Table 2). There is no difference in the age of diagnosis in females among the race and regions. The age of diagnosis remains around 35-40 years with the exception of other races in the colonias counties, as indicated in Figure 7. There is not a younger age for Black and Hispanic female diagnosis of HIV as hypothesized.

\section{Conclusion}

The age at diagnosis did not have any correlation with the pediatric HIV rate as hypothesized. It was also unaffected by access to healthcare, race and ethnicity, and the percent of Black and Hispanic populations as hypothesized. Although not statistically shown in this study, the age at diagnosis was significantly younger in the lower income colonias counties as hypothesized. While the female HIV rate was highest in the two urban areas, the pediatric HIV rate was highest in the Houston area, but slightly higher in the colonias than the Dallas area, 
contrary to expectation. Access to healthcare did not show any correlation with pediatric HIV. While pediatric HIV had a strong positive correlation with the Black population as expected, there was an unexpected negative correlation with the Hispanic population.

Despite the lack of access to healthcare and poverty across the colonias counties, they still have lower female HIV rates compared to the urban areas. But when assessed as a whole, the pediatric rate within the colonias is higher than the Dallas- Fort Worth Area. Also, the young age at diagnosis is somewhat reflected in the pediatric HIV rates. The colonias counties have the youngest average age at diagnosis, and a higher pediatric HIV rate than the Dallas-Fort Worth Area. The Houston-Galveston Area has the highest HIV rates, but an age at diagnosis similar to the Dallas-Fort Worth area.

As the correlations present only relative results, this study is analyzed by relativity, due to the limitations of data availability and the small number of cases in the Texas colonias counties. The maps (Figures 2 and 3) clearly display the congregation of HIV in the urban areas rather than in the colonias counties. Despite the poverty and poor living conditions in the colonias of the Texas-Mexico border counties, the metropolitan areas of Texas still have higher rates of HIV when assessing rates by county. Many further studies can be conducted as to why the urban areas tend to harbor much greater rates of HIV infection among the population. The effect of population density on infection, due to the exponential growth and availability of sexual partners, is an example for another study. Also this study can be expanded to analyze pediatric HIV and HIV in women throughout the rest of Texas, other states in the US, or in other countries. Although pediatric HIV has declined significantly in the US, in 2009, there were about 2.5 million children under 15 living with HIV in the world (WHO, 2010). Much research is still necessary to decrease the extremely high and rising HIV rate in women in Africa. This is the 
necessary research for tomorrow. Thus in doing this study, the results can hopefully be applied to curb the rampant HIV in Africa.

Finally, the higher rate of pediatric HIV in the colonias compared to Dallas requires further research and focused attention. Better screening of pregnant mothers and increased prenatal care in the colonias is critically needed to reduce vertical transmission. The strong correlation of female HIV rates and pediatric HIV rates, suggest that efforts to educate and provide women with resources can help to lessen pediatric HIV rates everywhere. We need to look to women and their living environment to prevent infection and keep their children from infection. This research hopefully provides an important contribution to further research and possible public health interventions addressing pediatric and maternal HIV infection. 


\section{References}

The Center for Disease Control and Prevention. (2006). HIV/AIDS Basic Statistics. Retrieved from http://www.cdc.gov/hiv/topics/surveillance/basic.htm

The Center for Disease Control and Prevention. (2010a). HIV/AIDS in Women. Retrieved from http://www.cdc.gov/hiv/topics/women/

The Center for Disease Control and Prevention. (2010b). HIV among Hispanic/Latinos. Retrieved from http://www.cdc.gov/hiv/hispanics/index.htm

The Center for Disease Control and Prevention. (2010c). HIV among African Americans. Retrieved from http://www.cdc.gov/hiv/topics/aa/index.htm

The Center for Disease Control and Prevention. (2010d). Human Immunodeficiency Virus Infection (HIV) 2008 Case Definition. Retrieved from http://www.cdc.gov/ncphi/disss/nndss/casedef/aids2008.htm

Houston-Galveston Area Council. (2008).Counties. Retrieved from http://www.hgac.com/rds/directory/counties/default.aspx

Kaiser Family Foundation. (2000). Health Insurance Coverage and Access to Care Among African Americans. Retrieved from http://www.healthpolicy.ucla.edu/pubs/files/healthinsurancecoverageandaccesstocaream ongafrican\%20americans.pdf

Markides, K.S, \& Eschbach, K. (2005). Aging, migration, and mortality: current status of research on the Hispanic paradox. Journal of Gerontology, 60B(II), 68-75.

Mier, N, Ory, M.G, Zhan, D, Conkling, M, Sharkey, J.R, and Burdine, J.N. (2008). Healthrelated quality of life among Mexican Americans living in colonias at the Texas-Mexico border. Social Science and Medicine, 66 (8), 1760-1771.

Morbidity and Mortality Weekly Report. Advancing HIV prevention: New strategies for a changing epidemic-United States, 2003. MMWR Morbidity and Mortality Weekly Report. 2003 Apr 18; 52(15), 329-332.

Morbidity and Mortality Weekly Report. Racial/ethnic disparities among children with diagnoses of perinatal HIV infection-34 states, 2004-2007 . (2010). MMWR Morbidity and Mortality Weekly Report, 2010 Feb 5; 59(4), 97-101.

Peterman, T.A, Lindsey, C.A, Selik, R.M. (2005). This place is killing me: A comparison of counties where the incidence rates of AIDS increased the most and the least. American Journal of Infectious Diseases, 191(1), S123-S126. 
Peters, V.B, Liu, K.L, Robinson, L.G, et al. (2008). Trends in perinatal HIV prevention in New York City, 1994-2003. American Journal of Public Health, 98(10), 1857-1864.

Sikkema, K.J., et al. (1996). HIV risk behaviors among women living in low-income, inner-city housing developments. American Journal of Public Health, 86(8), 1123-1128.

Texas Department of State Health Services, (2010). 2010 Texas integrated epidemiologic profile for HIV/AIDS prevention and services planning: HIV/AIDS in Texas (E13-11937). Retrieved from http://www.dshs.state.tx.us/hivstd/planning_profiles/0_Texas_Epi_Profile_2006

Texas Secretary of State. What is a colonia. Retrieved from http://www.sos.state.tx.us/border/colonias/what_colonia.shtml

Wallisch, Lynn. Texas Department of State Health Services, Texas Commission on Alcohol and Drug Abuse. (1998). 1996 survey of substance use on the Texas-Mexico border and in colonias. Austin, TX. Retrieved from http://www.dshs.state.tx.us/sa/research/adult/1298border.pdf

World Health Organization. (2010). Global report: UNAIDS report on the global AIDS epidemic 2010. Retrieved from http://www.unaids.org/globalreport/Global_report.htm 
Table 1. Spearman's rho Correlation Coefficients and Significance

\begin{tabular}{|c|l|l|l|}
\hline & Female HIV Rate & Pediatric HIV Rate & \multicolumn{1}{|c|}{$\begin{array}{c}\text { Average Age of } \\
\text { Diagnosis in } \\
\text { Females }\end{array}$} \\
\hline Female HIV Rate & $* *$ & $\mathrm{R}=.696, \mathrm{p}=.000$ & $\mathrm{R}=.380, \mathrm{p}=.009$ \\
\hline Pediatric HIV Rate & $\mathrm{R}=.696, \mathrm{p}=.000$ & $* *$ & Not significant \\
\hline $\begin{array}{c}\text { Average Age of } \\
\text { Diagnosis in } \\
\text { Females }\end{array}$ & $\mathrm{R}=.380, \mathrm{p}=.009$ & Not significant & $* *$ \\
\hline $\begin{array}{c}\text { Percent Population } \\
\text { Uninsured }\end{array}$ & $\mathrm{R}=-.321, \mathrm{p}=.03$ & Not significant & $\mathrm{R}=-.458, \mathrm{p}=.001$ \\
\hline Median Income & $\mathrm{R}=.449, \mathrm{p}=.002$ & $\mathrm{R}=.561, \mathrm{p}=.000$ & Not significant \\
\hline $\begin{array}{c}\text { Percent Population } \\
\text { Unemployed }\end{array}$ & Not significant & Not significant & Not significant \\
\hline $\begin{array}{c}\text { Primary Care } \\
\text { Provider Rate (per } \\
\text { 100,000) }\end{array}$ & Not significant & Not significant & Not significant \\
\hline $\begin{array}{c}\text { Percent Black of } \\
\text { Total Population }\end{array}$ & $\mathrm{R}=.731, \mathrm{p}=.000$ & $\mathrm{R}=.653, \mathrm{p}=.000$ & Not significant \\
\hline $\begin{array}{c}\text { Percent White of } \\
\text { Total Population }\end{array}$ & Not significant & $\mathrm{R}=.323, \mathrm{p}=.029$ & $\mathrm{R}=.291, \mathrm{p}=.050$ \\
\hline $\begin{array}{c}\text { Percent Hispanic of } \\
\text { Total Population }\end{array}$ & $\mathrm{R}=-.372, \mathrm{p}=.011$ & $\mathrm{R}=-.440, \mathrm{p}=.002$ & Not significant \\
\hline
\end{tabular}


Table 2. Comparison of Female and Pediatric HIV Rates by Region

\begin{tabular}{|l|c|c|}
\hline & $\begin{array}{c}\text { Female HIV Rate (per } \\
100,000 \text { women) }\end{array}$ & $\begin{array}{c}\text { Pediatric HIV Rate (per } \\
100,000 \text { children <13 years) }\end{array}$ \\
\hline Dallas-Fort Worth Area & 232.7 & 17.9 \\
\hline Houston-Galveston Area & 352.8 & 36.3 \\
\hline Colonias Counties & 82.6 & 19.6 \\
\hline
\end{tabular}


Figure 1. Dallas-Fort Worth Area, Houston-Galveston Area, and Texas-Mexico Border Colonias Counties

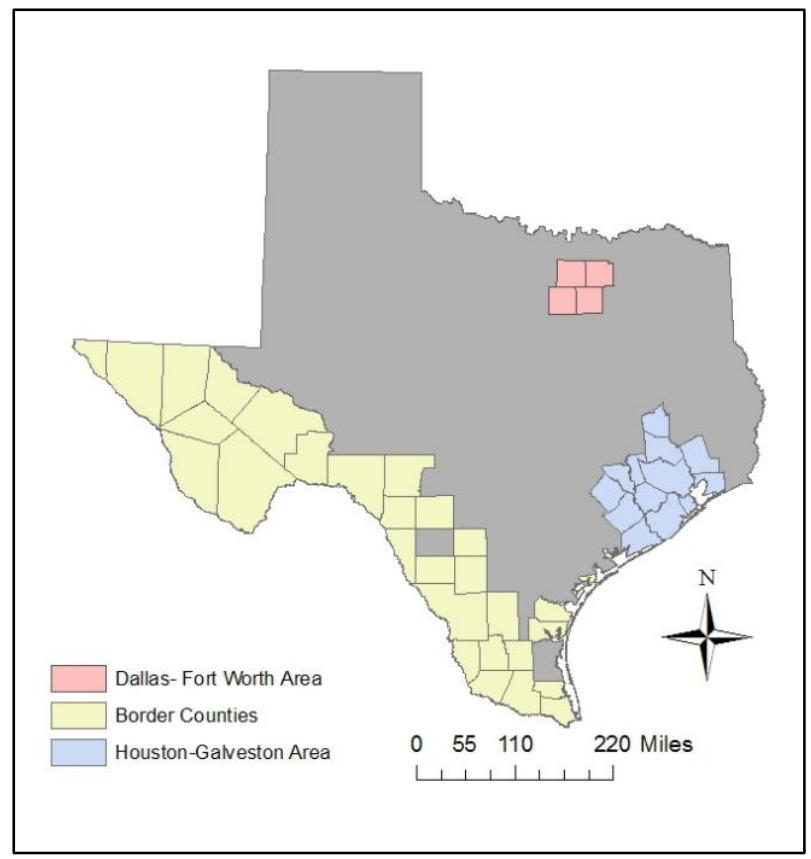


Figure 2. Female HIV Rates in the Dallas-Fort Worth Metroplex, Houston-Galveston Area, and Border Colonias Counties from 1980-2009

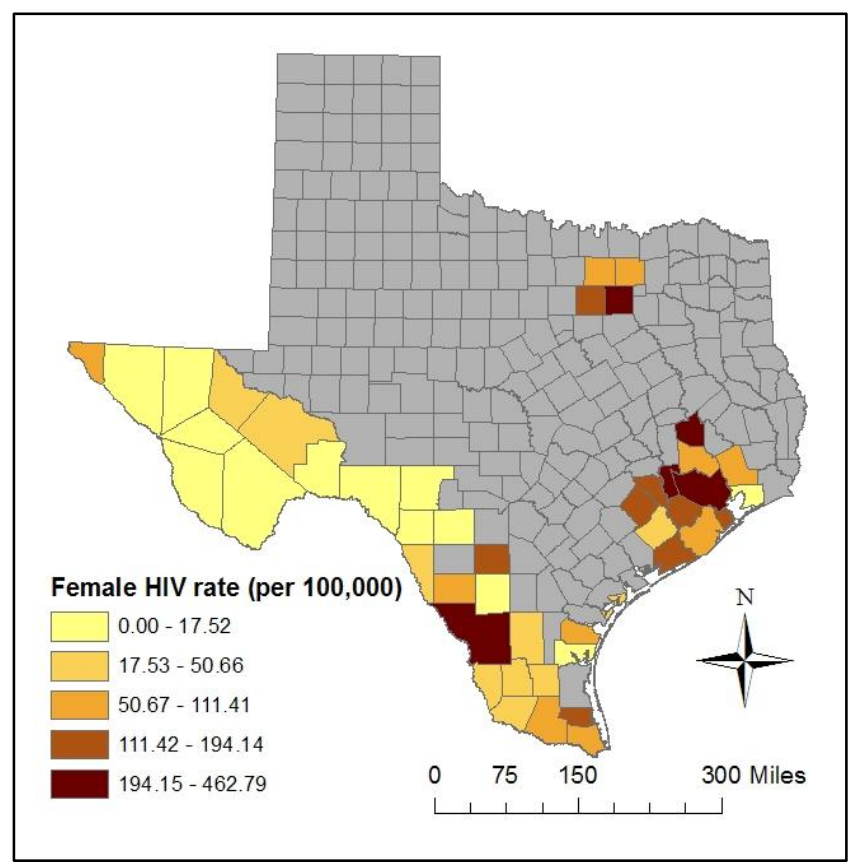


Figure 3. Pediatric HIV Rates in the Dallas-Fort Worth Metroplex, Houston-Galveston Area, and Border Colonias Counties from 1980-2009

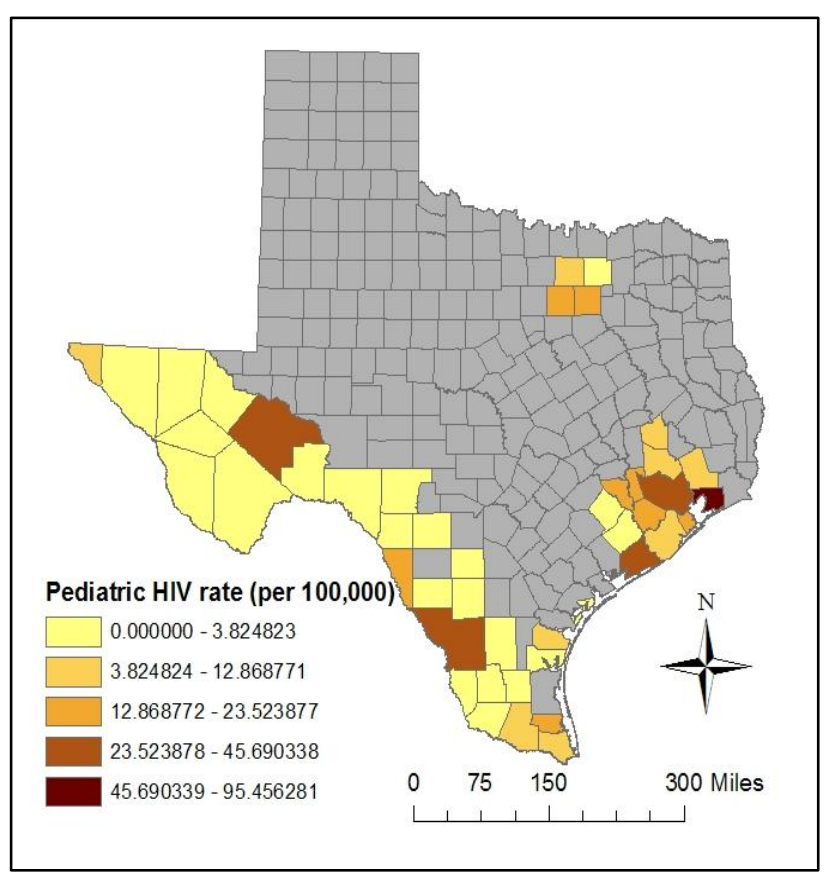


Figure 4. HIV Rate in the Dallas-Fort Worth Metroplex, Border Colonias Counties, and Houston-Galveston Area from 1980-2009

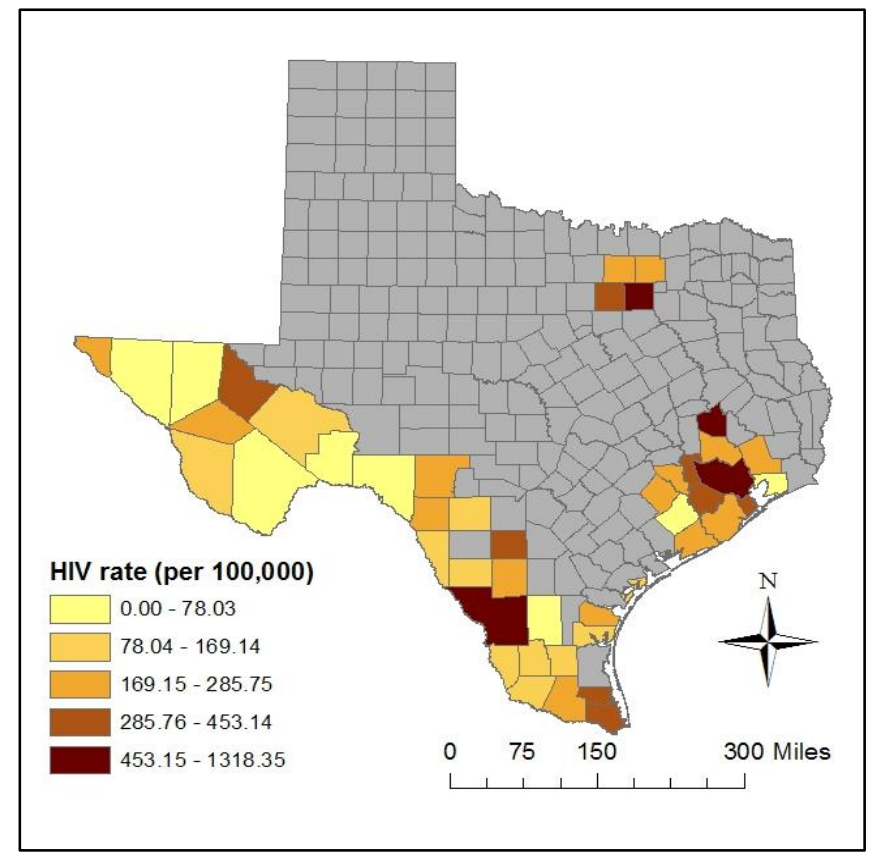


Figure 5. Comparison of HIV Diagnosis Age by Area

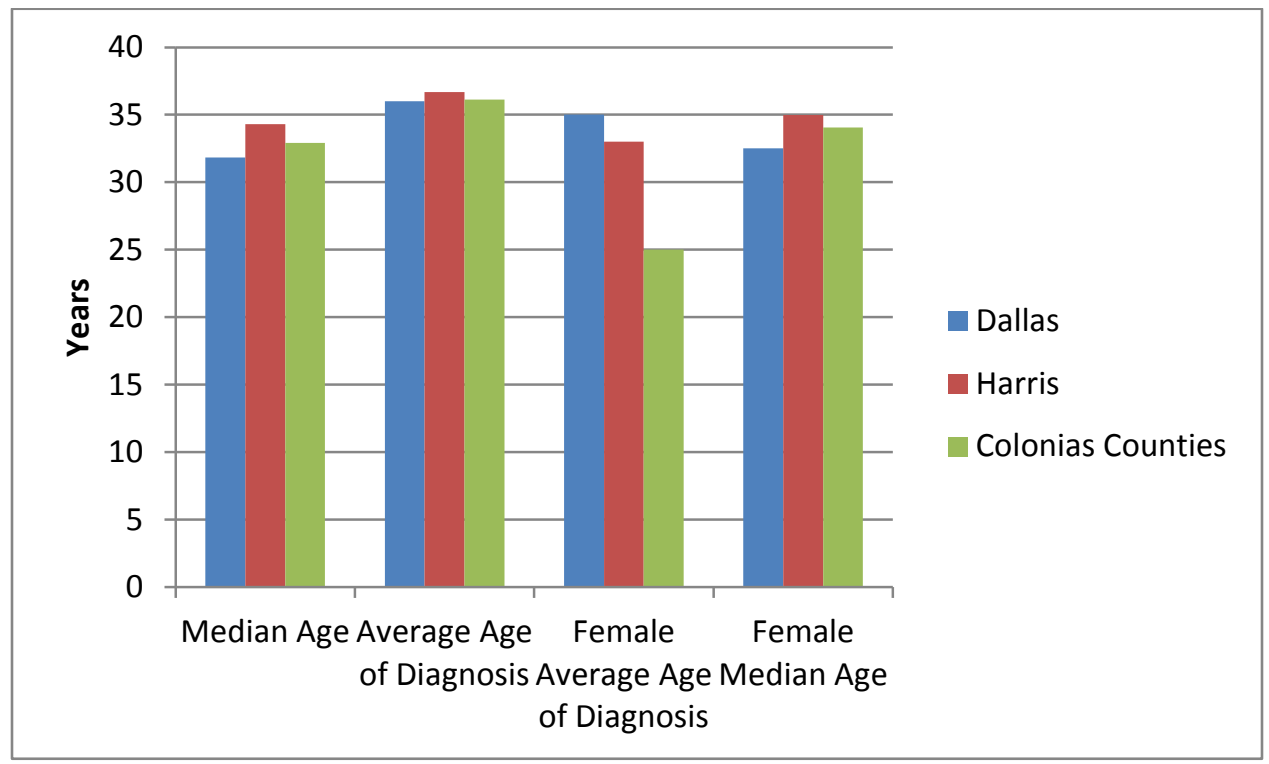


Figure 6. Comparison of Age of HIV Diagnosis (in years) in Women

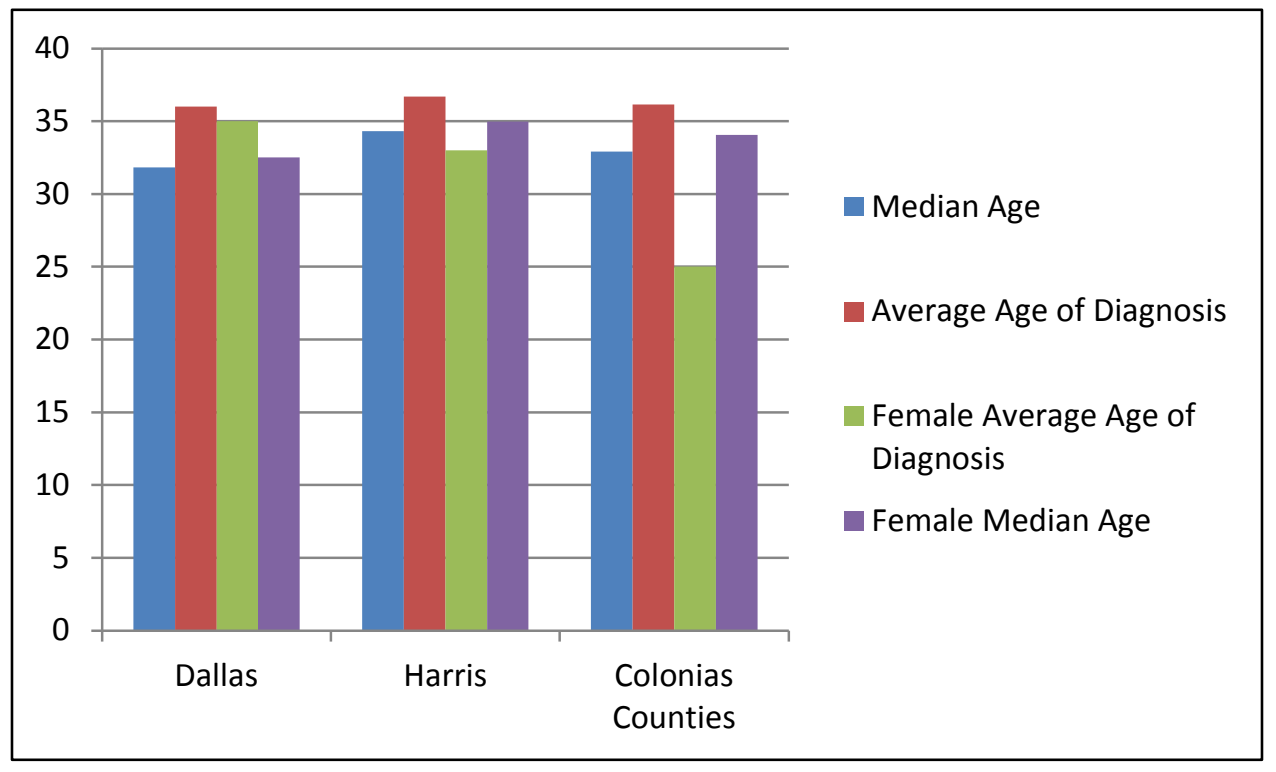


Figure 7. Comparison of Age of HIV Diagnosis (in years) in Women and Race and Ethnicity

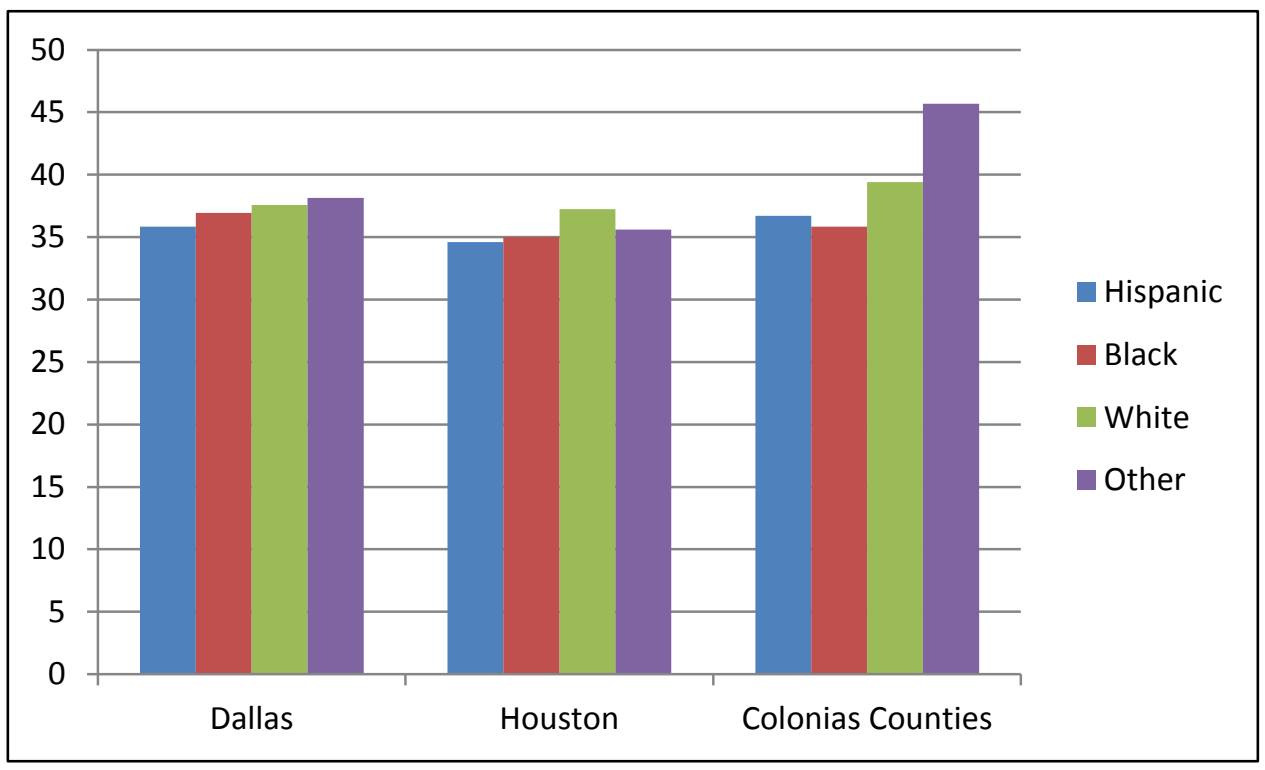

